\title{
MODELO DE ANÁLISE DAS DEMONSTRAÇÕES CONTÁBEIS PELO MÉTODO INTEGRADO
}

\author{
Alexandre André Feil ${ }^{1}$, Adriano José Azeredo ${ }^{2}$, Claus Haetinger ${ }^{3}$, Ari Kunzel $^{4}$ \\ 1,2,3,4 Universidade do Vale do Taquari - UNIVATES \\ ${ }^{1}$ afeileunivates.br \\ ${ }^{3}$ adrianojeunivates.br \\ ${ }^{3}$ chaeteunivates.br \\ ${ }^{4}$ arikeunivates.br
}

\section{Resumo}

Este estudo visa estruturar um modelo complementar para a análise das demonstrações contábeis tradicional por meio do enfoque integrado e estruturado por meio da regressão não-linear, especificamente as funções polinomiais de grau 2. Para isto selecionou-se uma empresa de médio porte localizada no sul do Brasil, cujas demonstrações contábeis do período de 20x0 a 20x4 serviram para calcular os índices de liquidez, estrutura de capital, rentabilidade e solvência, a partir dos quais foi elaborada uma previsão futura ou regressão de 20x5 a 20x6 através de funções polinomiais de grau 2. A função polinomial pode ser utilizada por meio do software Microsoft Office Excel ${ }^{\circledR}$, amplamente difuso no meio corporativo. Os resultados apresentados pelas linhas de tendência obtiverem, em média, um coeficiente de determinação de 0,8529, que expressa uma exatidão ou confiabilidade da projeção futura dos índices e coeficientes de 85,29\%. Portanto, a análise das demonstrações contábeis em conjunto com a linha de tendência, faz com que o analista tenha um mecanismo de alarme quando a previsão apontar para índices com valores críticos e identifique a situação passada e futura da corporação. A análise tradicional das demonstrações contábeis não pode ser ignorada, entretanto, pelo grau de subjetividade utilizada neste processo, a inclusão da análise integrada reduz a subjetividade e atribui maior confiabilidade e maior precisão na elaboração da sua conclusão, provendo os tomadores de decisão com uma visão proativa dos acontecimentos antes do ocorrido, podendo-se alterar o rumo da corporação.

Palavras-chave: Análise das demonstrações contábeis; função polinomial; linhas de tendência.

\section{ANAL YSIS MODEL OF FINANCIAL STATEMENTS FOR THE INTEGRATED METHOD}

\section{Abstract}

This study aims to structure a complementary model for the analysis of traditional financial statements through integrated and structured approach to non-linear regression using degree of polynomial functions 2. For this, we selected a medium-sized company located in southern Brazil, whose financial statements for the period of the $20 \times 020 \times 4$ served to calculate the liquidity ratios, capital structure, profitability and solvency, from which was prepared a future prediction or regression 20x5 $20 X 6$ through the degree of polynomial functions 2 . The polynomial function can used by Microsoft Office Excel ${ }^{\circledR}$ software, widely diffused in the corporate environment. The results presented by the trend lines obtain, on average, a coefficient of determination of 0.8529, which expresses the accuracy or reliability of future projection of the 
indices and coefficients of $85.29 \%$. Therefore, the analysis of financial statements together with the trend line, makes the analyst has an alarm mechanism when the forecast point to indices with critical values and identify past and future situation of the corporation. The traditional analysis of the financial statements cannot be ignored, however, the degree of subjectivity used in this process, including integrated analysis reduces subjectivity and gives greater reliability and greater precision in preparing its completion, providing decision makers with a vision proactive of events occurred before, being able to change the direction of the corporation.

Keyword: Analysis of the financial statements; polynomial function; Trendlines

\section{Introdução}

A análise das demonstrações contábeis por meio de índices e quocientes constitui uma ferramenta consagrada na mensuração e avaliação do desempenho econômico, financeiro e patrimonial das corporações. Esta análise compreende uma das formas de avaliação utilizada pelos stakeholders exógenos por meio de três enfoques distintos, a análise tradicional, a integrada e a estruturada (SANTOS; NOVA, 2005).

A análise tradicional das demonstrações contábeis centra-se na avaliação artesanal, possui dependência de capacidade técnica e da experiência do analista, não é padronizada, requer demanda de tempo na preparação das informações e conclusões, os resultados podem não ser confiáveis, analisa apenas dados históricos e pode ser uma etapa da organização das informações que precede a aplicação de modelos estatísticos (BRAGA, NOSSA; MARQUES, 2004). Com base nestas deficiências, em especial, a subjetividade, surgem os modelos integrados de análise.

A análise integrada interpreta o desempenho com base na análise conjunta e utiliza-se de métodos quantitativos e estatísticos para desenvolver fatores determinantes, previsões de cenários, análises discriminantes, modelos estatísticos, e de dados históricos como alicerce de análise (SANTOS; NOVA, 2005). Nesta lógica, percebe-se que a análise do desempenho econômico-financeiro está migrando de uma análise subjetiva a uma estruturada e integrada.

A utilização de métodos estatísticos na avaliação deste desempenho pode ser denominada de contabilometria (IUDÍCIBUS, 1982), na qual utiliza-se a estatística para predição de cenários com o auxílio da matemática, por exemplo, a regressão linear e não-linear, e da informática (projeção de dados, índices e relatórios) para agregar soluções gerenciais, planejamento e controle (SILVA; CHACON; SANTOS, 2005; BRIGNONI; RUBERTO, 2015). Portanto, os métodos estatísticos e quantitativos auxiliam na apuração dos índices, na comparações dos dados entre diferentes períodos e na interpretação dos resultados, tornando-se assim, uma valiosa ferramenta gerencial (BRIGNONI; RUBERTO, 2015).

O modelo de análise das demonstrações que abrange uma visão holística e integrada da saúde econômica-financeira de fácil manuseio e baixo custo é escasso (BRAGA, NOSSA; MARQUES, 2004). Além disso, existem indicadores contábeis, tais como termômetro de insolvência de Kanitz, desde a década de 1970, , porém este prevê a falência e não centra-se na ideia de geração de valor as corporações (SCALABRIN; ALVES, 2003). Diante deste contexto, este estudo, objetiva apresentar um modelo de análise das demonstrações contábeis por meio do enfoque integrado e estruturado com regressão não-linear.

Este estudo justifica-se pelo número de pedido de falência empresarial (1.783), no país, no ano de 2015 (SERASA, 2015), sendo distribuído entre 923 micro e pequenas empresas, 415 médias empresas e 448 de grande porte. A Exame (2015) aponta que os pedidos de falência e de 
recuperação judicial cresceram 55,4\% de 2014 a 2015. Sendo assim, este estudo contribui com a implementação da regressão não-linear nas análises das demonstrações contábeis para prever os rumos das organizações em curto e médio prazo, pois com a disponibilização de informações de cenários futuros pode-se agir para contornar ou minimizar os impactos nas organizações. Além disso, contempla uma ferramenta de análise com fácil utilização e baixo custo, o que facilita sua utilização, em especial, em empresas de micro e pequeno porte.

\section{Referencial Teórico}

\subsection{Análise das demonstrações contábeis}

A contabilidade é uma ciência que estuda, controla e registra, de forma cronológica e sistematizada, os fatos econômicos e financeiros (IUDICIBUS, 2009; ASSAF NETO, 2010). Hendriksen e Van Breda (2009) salientam que a contabilidade tem como objeto de estudo o patrimônio das entidades composto por bens, direitos e obrigações. Já a sua finalidade é de captar, registrar, acumular, estudar e interpretar os fenômenos ocorridos num período de tempo na gestão patrimonial da entidade para prover os stakeholders com demonstrações contábeis e análises de natureza financeira, patrimonial e econômica para tomadas de decisões (ASSAF NETO, 2010).

No Brasil, as demonstrações contábeis principais constituem o Balanço Patrimonial (BP) e a Demonstração do Resultado do Exercício (DRE); e as auxiliares relacionam-se a Demonstração do Fluxo de Caixa (DFC), a Demonstração do Valor Adicionado (DVA), a Demonstração das Mutações do Patrimônio Líquido (DMPL) e as Notas Explicativas (NE) (MATARAZZO, 2008; IUDICIBUS, 2009). A técnica de análise destas demonstrações, é tão antiga quanto a própria contabilidade (HENDRIKSEN; VAN BREDA, 2009; MARION, 2010).

A ênfase na sua utilização ocorreu a partir de 1885, quando o conselho executivo da associação dos Bancos em Nova York recomendou que os tomadores de créditos apresentassem os ativos e passivos por escrito aos analistas financeiros (MATARAZZO, 2008). A partir de 1915 a análise das demonstrações contábeis tornou-se obrigatória para as instituições financeiras dos Estados Unidos na concessão de empréstimos.

No Brasil, a análise das demonstrações contábeis foi utilizada como técnica de concessão de empréstimos difundindo-se a partir da década de 1970 (MATARAZZO, 2008). A finalidade inicial, desta análise, compreendia estudar o desempenho econômico-financeiro da corporação por determinado período de tempo, servindo como base para a administração financeira e despertando enorme interesse para os administradores endógenos das organizações e dos diversos segmentos de analistas exógenos (ASSAF NETO, 2010; MATARAZZO, 2008).

A análise das demonstrações contábeis é a arte de "[...] saber extrair relações úteis, para o objetivo econômico que tivermos em mente, dos relatórios contábeis tradicionais e de suas extensões e detalhamento, se for o caso" (IUDICIBUS et al., 2007, p. 5). A ideia de "[...] analisar uma demonstração é decompô-la nas partes que a formam, para melhor interpretação de seus componentes" (FRANCO, 1989, p. 93). Braga e Almeida (2008, p. 14) salientam que é "[...] como uma arte que reúne conhecimentos teóricos, experiência prática e, sobretudo, sensibilidade, argúcia, empenho e bom-senso".

Neste sentido, o principal objetivo da análise das demonstrações contábeis é formar uma conclusão sobre o desempenho econômico e financeiro de uma entidade durante determinado período, bem como obter informações que auxiliem na complementação das projeções futuras 
dos dados (HOUSTON; BRIGHAM, 1999; SCALABRIN; ALVES, 2003; MARTINS, 2005). Franco (1989) e Scalabrin e Alves (2003) complementam que a análise contribui com o aumento do valor informativo da contabilidade, agregando suporte para tomadas de decisões. Para tanto, o profissional analista não pode apenas se deter a esta área do conhecimento, mas deve conhecer outras como a economia, a administração geral, o marketing e o direito (SILVA, 2006).

O elemento de partida da análise é o BP, que reflete a posição das contas patrimoniais, evidenciando as fontes (origem) e investimentos (aplicação) de recursos, indispensável ao conhecimento por meio de índices e coeficientes da situação financeira, patrimonial e econômica da corporação (ASSAF NETO, 2010).

\section{2 Índices e coeficientes contábeis}

Os índices e coeficientes extraídos das demonstrações contábeis evidenciam a relação entre as contas ou grupo de contas e fornecem uma visão ampla da situação econômico-financeira da organização (MATARAZZO, 2008). O conjunto de índices e coeficientes está representado pelo índice de liquidez (geral, corrente e seca), a estrutura de capital (participação de capital de terceiros, composição do endividamento, imobilização do patrimônio líquido e a dependência bancária), a rentabilidade (margem líquida e rentabilidade do patrimônio líquido) e a solvência (capital de giro próprio, necessidade de capital de giro e o saldo de tesouraria) (QUADRO 1).

Quadro 1 - Índices de liquidez, estrutura de capital, rentabilidade e solvência

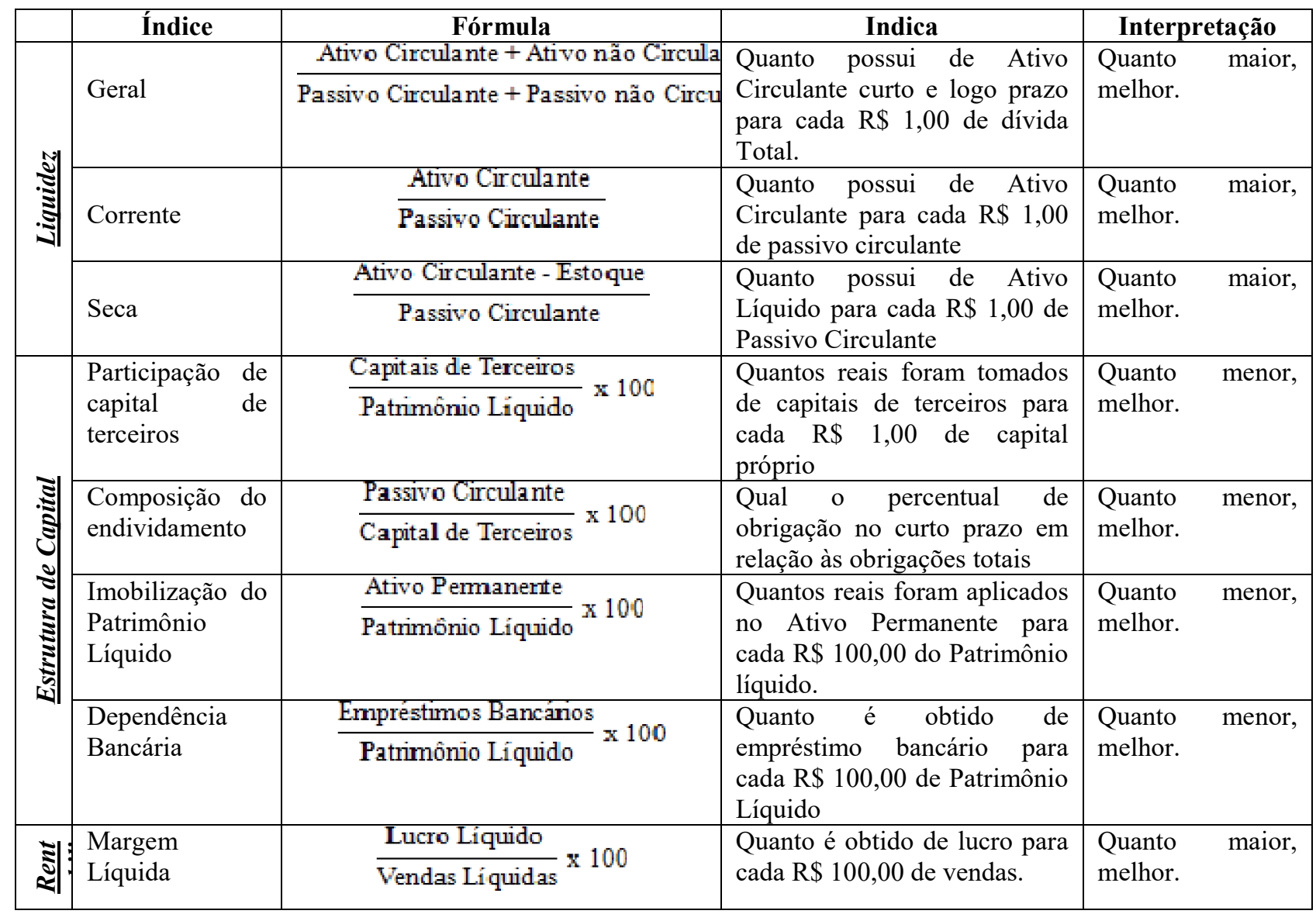




\begin{tabular}{|c|c|c|c|c|}
\hline & $\begin{array}{l}\text { Rentabilidade } \\
\text { do Patrimônio } \\
\text { líquido }\end{array}$ & $\frac{\text { Lucro Liquido }}{\text { Patrimônio Liquido Médio }} \times 100$ & $\begin{array}{l}\text { Quanto é obtido de lucro para } \\
\text { cada R\$ } 100,00 \text { de capital } \\
\text { próprio investido }\end{array}$ & $\begin{array}{l}\text { Quanto maior, } \\
\text { melhor. }\end{array}$ \\
\hline \multirow{3}{*}{ 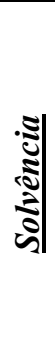 } & $\begin{array}{l}\text { Capital de giro } \\
\text { Próprio }\end{array}$ & Ativo Cir culante-Passivo Circulante & $\begin{array}{l}\text { Quanto de capital de giro } \\
\text { próprio está à disposição. }\end{array}$ & $\begin{array}{l}\text { Quanto Maior, } \\
\text { Melhor. }\end{array}$ \\
\hline & $\begin{array}{l}\text { Necessidade de } \\
\text { Capital de giro }\end{array}$ & Ativo Circulante Op. -Passivo Circulan & $\begin{array}{l}\text { Quanto é necessário de } \\
\text { recursos para financiar o giro }\end{array}$ & $\begin{array}{l}\mathrm{ACO}>\mathrm{PCO}= \\
\text { Ruim } \\
\mathrm{ACO}<\mathrm{PCO}=\text { Boa } \\
\mathrm{ACO}=\mathrm{PCO}=\text { Boa }\end{array}$ \\
\hline & $\begin{array}{l}\text { Saldo de } \\
\text { Tesouraria }\end{array}$ & $\frac{\text { Saldo em Tesouraria }}{\text { Vendas Líquidas + Impostos }} \times 100$ & $\begin{array}{l}\text { Quantos de saldo em } \\
\text { tesouraria existe em relação as } \\
\text { vendas }\end{array}$ & $\begin{array}{l}\text { Quanto } \\
\text { Melhor }\end{array}$ \\
\hline
\end{tabular}

Fonte: (SCHRICKEL, 2000; BLATT, 2001; PADOVEZE, 2004; SILVA, 2004; MATARAZZO, 2008; ASSAF NETO, 2010; IUDICIBUS, 2009).

A análise desse conjunto de índices de forma isolada revela apenas conclusões parciais, sendo assim, a análise deve considerar o conjunto de índices e, além disto, aliadas a outras áreas de investigação (SCHRICKEL, 2000). Como forma de exemplificação, pode-se alavancar a rentabilidade da empresa captando recursos de terceiros, porém os custos dessa captação devem ser inferiores aos ganhos obtidos na sua aplicação na atividade operacional ou financeira (AZEREDO, 2008; HOJI, 2004). As relações de liquidez, endividamento e rentabilidade, inibem a organização de usufruir de liquidez, baixo custo financeiro e alta rentabilidade ao mesmo tempo, pois alta liquidez implica baixo risco e menor rentabilidade (MYERS, 2001; PEROBELLI; PEREIRA; DAVID, 2006; AZEREDO, 2008). Destes indicadores, destaca-se o lucro como mais significante (CHANG; CHANG; HSIN, 2006), o qual sinaliza uma proxy inversa para custos e despesas (MEUSE et al., 2004).

Depreende-se que a análise não pode conter vieses nas conclusões sobre a situação econômica e financeira da organização. A leitura na íntegra das demonstrações contábeis e relatórios auxiliares e a escolha dos índices são cuidados a serem tomados para evitá-los (AZEREDO, 2008).

As análises pelo enfoque tradicional utilizam apenas os dados históricos da entidade, mas num conceito mais moderno, além de utilizar os dados históricos, utiliza-se a técnica de regressão para previsão dos dados (MATARAZZO, 2008). Neste sentido, Pereira, Pedrosa Júnior e Ramos (2006) complementam que esta técnica supera a análise tradicional (análise de dados históricos) apresentando maior volume e qualidade de informações às tomadas de decisões. Blatt (2001), Matarazzo (2008) e Iudicibus (2009) evidenciam uma perspectiva de que os índices e coeficientes resultantes destas análises apenas apresentam uma tendência futura da situação da corporação, mas sem rigor estatístico de regressão.

\subsection{Técnicas de regressão e estudos anteriores}

As regressões representam "[...] um recurso formal para expressar alguma tendência da variável dependente $y$ quando relacionada com a variável independente $x[\ldots]$ ]" (BASSANEZI, 2006, p. 54). Callegari-jacques (2003) e Motta (2006) acrescentam que a regressão de dados parte de um gráfico de dispersão de pontos $(x, y)$ para verificar se a regressão possui um coeficiente de determinação aceitável, evitando-se assim uma aplicação de regressão em dados não adequados.

$\mathrm{O}$ coeficiente de determinação $\left(\mathrm{R}^{2}\right)$ é uma medida de ajuste, ou seja, o percentual de variação na qual a linha de tendência ou regressão é explicada em função dos dados históricos utilizados 
(WEBSTER, 2006). Ainda salienta que a interpretação do $\mathrm{R}^{2}$ é entendida como a exatidão da regressão realizada.

Uma das técnicas empregadas na previsão (regressão ou linha de tendência) é a função polinomial utilizada para determinar valores que fogem do escopo de uma série temporal (WEBGRAPHING, 2013). A função polinomial de ordem 2 possui como característica uma linha de tendência contínua e suave sem cantos, quebras ou buracos (WEBGRAPHING, 2013). NATRELLA et al. (2010) salientam que as vantagens de utilização da função polinomial são resumidas em: a) possuem uma forma simples; b) têm suas propriedades bem conhecidas e compreendidas; c) possuem uma flexibilidade moderada nas formas; e d) são computacionalmente fáceis de usar. Destaca-se ainda que a utilização da função polinomial pode ser utilizada por meio do software Microsoft Office Excel, utilizado amplamente no meio corporativo.

A descrição de estudos anteriores que utilizaram a análise integrada por meio da estatística é importante, pois fortalece sua utilização. Alguns exemplos de aplicação estão descritos a seguir: a) Ocal et al. (2007) determinaram, com o auxílio da análise fatorial, os índices a serem utilizados na análise de tendência; b) Niemann, Schmidt e Neukirchen (2008) avaliam modelos de previsão de índices para corporações multinacionais; c) Scalabrin e Alves (2003) avaliam a capacidade de previsão, por meio de modelos matemáticos e econométricos, da geração de valor das empresas brasileiras; d) Tsaousoglou, Aretoulis e Kalfakakou (2013) avaliam o desempenho das demonstrações financeiras por meio de modelos de regressão múltipla; e) Ramalho e Silva (2013) discutem as principais características dos modelos de regressão para fornecer base teórica na utilização de regressão de índices financeiros; e f) Brignoni e Ruberto (2015) avaliam a forma que o método estatístico de regressão linear auxilia na análise dos índices financeiros.

\section{Procedimentos metodológicos}

Esta pesquisa caracteriza-se como quantitativa, pois utiliza-se da análise de regressão e de outros recursos estatísticos; como exploratória-descritiva em virtude da aplicação e descrição da relação entre a função polinomial de grau 2 e a análise tradicional das demonstrações contábeis; e ainda como documental considerando que as demonstrações contábeis objeto da análise não haviam recebido tratamento analítico (GIL, 1999; SILVA; MENEZES, 2005; OLIVEIRA, 2011).

A unidade de análise compreende uma organização de médio porte com capital fechado, localizada no Sul do Brasil. Esta organização autorizou a publicação apenas dos resultados das análises (índices e coeficientes). Os dados contabeis e financeiros desta organização foram utilizados em função de sua acessibilidade e disponibilidade. Os dados foram coletados em outubro de 2015 na área da controladoria da organização. Os relatórios contábeis disponibilizados pela organização compreendem o BP e a DRE referentes aos anos base de 20x0 a 20x4. O período temporal foi substituído por valores atemporais, pois neste estudo a importância centra-se em apresentar a utilização da regressão.

A tabulação dos dados foi realizada por meio de planilhas eletrônicas, e após apurou-se os índices e coeficientes, tais como o: a) liquidez corrente; b) liquidez geral; d) liquidez seca; e) participação de capital de terceiros; f) grau de imobilização; g) rentabilidade do patrimônio líquido; h) dependência bancária; i) capital de giro; j) capital circulante líquido; l) capital de giro próprio; m) margem líquida; n) endividamento geral; e o) evolução da receita operacional. Após a realização dos cálculos, os dados foram pareados em tabelas comparativas do período de 20x0 a $20 \times 4$. 
A partir dos índices e coeficientes apurados (20x0 a 20x4), foi elaborada uma previsão futura ou regressão de 20x5 a 20x6 através de funções polinomiais de grau 2. O software que foi utilizado para realizar a regressão é o Microsoft Office Excel ${ }^{\circledR}$. O emprego do software Excel na regressão é justificado pela praticidade de manuseio e sua disponibilidade nas corporações. Os resultados das regressões foram tabulados e apresentados em formato de gráficos para facilitar o entendimento da situação corporativa.

$O$ método de regressão utilizado compreende o coeficiente de determinação $\left(R^{2}\right)$ e seu resultado apresenta uma variação de 0 a 1 , ou seja, em $\mathrm{R}^{2}=1$, tem-se correlação perfeita, e quanto maior é o valor de $\mathrm{R}^{2}$ melhor é o ajuste da linha de tendência em relação à linha obtida pelos dados históricos (CALLEGARI-JACQUES, 2003; MOTTA, 2006).

A análise das demonstrações contábeis apresenta limitações relacionadas: à inflação, dado que os registros contábeis são baseados no valor original da transação e ignoram as alterações do poder aquisitivo da moeda; a confiabilidade das informações, pois as demonstrações podem expressar imprecisão sobre a real situação do patrimônio e econômica da organização examinada; e a defasagem temporal entre as datas do registro contábil e da realização da análise (SAPORITO, 2005).

\section{Resultados}

\subsection{Análise dos Índices de liquidez}

A apuração dos índices de liquidez corrente, geral e seca, do período de 20x0 a 20x4 ocorreram com base nas informações do BP. Já a regressão do ano de 20x5 e 20x6 foram apuradas com base nos dados históricos dos resultados dos índices de liquidez (TABELA 1).

Tabela 1 -Série temporal histórico e a regressão dos índices de liquidez

\begin{tabular}{l|c|c|c|c|c|c|c}
\hline & \multicolumn{4}{c|}{ Índices históricos } & \multicolumn{3}{c}{ Regressão (R $\left.^{2}\right)$} \\
\hline & $20 \times 0$ & $20 \times 1$ & $20 \times 2$ & $20 \times 3$ & $20 \times 4$ & $20 \times 5$ & $20 \times 6$ \\
\hline Liquidez Corrente & 1,70 & 1,60 & 1,66 & 1,26 & 1,10 & $0,73^{1}$ & $0,27^{1}$ \\
\hline Liquidez Geral & 1,50 & 1,48 & 1,33 & 1,12 & 1,08 & $0,90^{2}$ & $0,73^{2}$ \\
\hline Liquidez Seca & 0,70 & 0,50 & 0,66 & 0,50 & 0,20 & $0,22^{3}$ & $0,12^{3}$ \\
\hline
\end{tabular}

Fonte: Dados da pesquisa.

Legenda: ${ }^{1}$ Função Polinomial $\left(\mathrm{y}=-0,0414 \mathrm{x}^{2}+166,31 \mathrm{x}-166898\right), e \mathrm{R}^{2}=0,911 .{ }^{2}$ Função Polinomial $\left(\mathrm{y}=-0,0071 \mathrm{x}^{2}\right.$ $+28,58 \mathrm{x}-28587), e \mathrm{R}^{2}=0,9392 .{ }^{3}$ Função Polinomial $\left(\mathrm{y}=-5 \mathrm{E}-0,5 \mathrm{x}^{2}+0,1005 \mathrm{x}\right), e \mathrm{R}^{2}=0,6460$.

A análise dos índices históricos de liquidez corrente e geral (TABELA 1) apontam que a empresa possui recursos financeiros maiores que 1,0, ou seja, tem condições no curto prazo de saldar suas obrigações. Apesar de apresentarem uma constante diminuição ao longo do período histórico analisado. A liquidez seca apresenta um índice inferior a 1,0, sendo assim, a empresa não consegue saldar as dívidas de curto prazo, desconsiderando-se o saldo do estoque (ativo circulante), pois depende da venda do estoque para pagar suas obrigações.

A regressão apurada com auxílio das linhas de tendências (GRÁFICO 1), pela função polinomial de grau 2, revelam que os índices de liquidez foram previstos com uma precisão $\mathrm{R}^{2}$ de 91,1\% (corrente), 93,92\% (geral), 64,60\% (seca). 
Gráfico 1 - Regressão dos índices de liquidez.

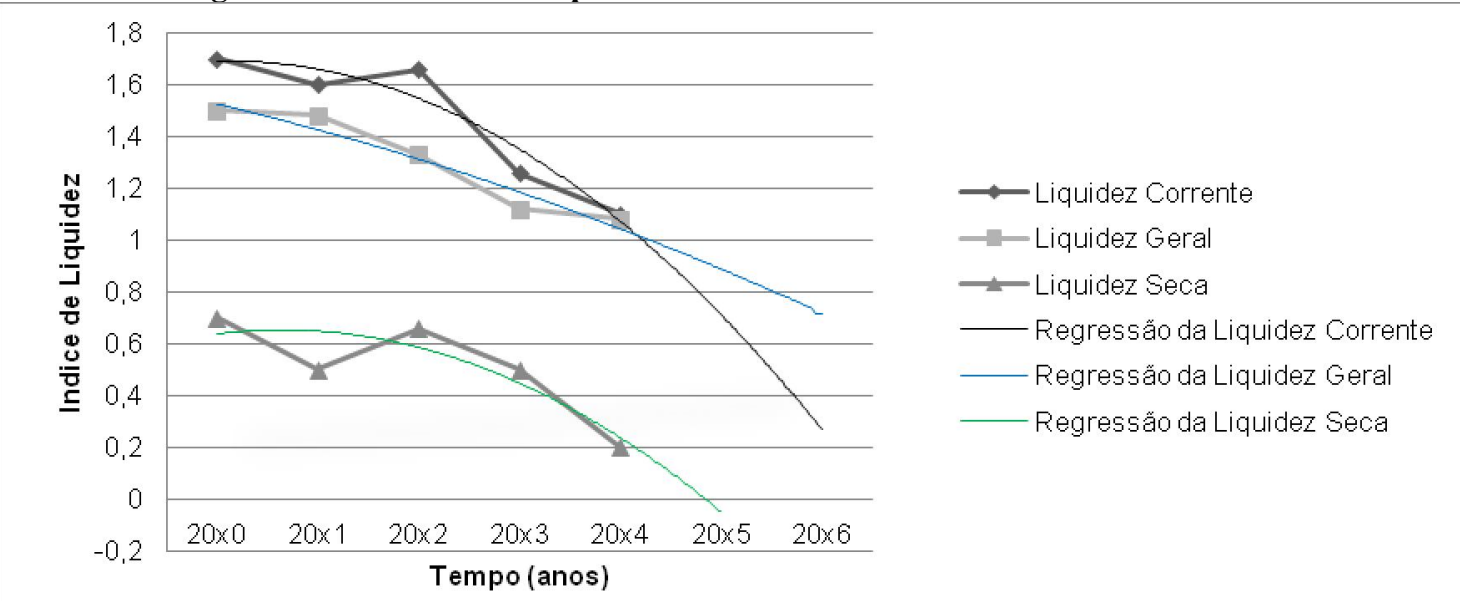

Fonte: Dados da pesquisa.

Estes resultados mostram um coeficiente de determinação com uma alta precisão. Portanto, a precisão da previsão é confiável para os anos de 20x4 e 20x5, entretanto apresentam uma piora destes índices.

\subsection{Análise da estrutura de capital}

O índice da participação do capital de terceiros revela que a obrigação da entidade é gradativamente maior ano após ano $(20 \mathrm{x} 0$ a 20x4), portanto, apresentando alto endividamento (TABELA 2).

Tabela 2 - Série temporal histórico e a regressão da estrutura de capital

\begin{tabular}{l|c|c|c|c|c|c|c}
\hline & \multicolumn{4}{|c|}{ Índices históricos } & \multicolumn{3}{c}{ Regressão $\left(\mathbf{r}^{2}\right)$} \\
\hline & $20 \times 0$ & $20 \times 1$ & $20 \times 2$ & $20 \times 3$ & $20 \times 4$ & $20 \times 5$ & $20 \times 6$ \\
\hline $\begin{array}{l}\text { Participação do Capital de Terceiros } \\
(\%)\end{array}$ & 120 & 144 & 173 & 350 & 370 & $510^{4}$ & $654^{4}$ \\
\hline Grau de Imobilização do PL (\%) & 21 & 31 & 42 & 59 & 70 & $87^{5}$ & $102^{5}$ \\
\hline Dependência Bancária (\%) & 90 & 107 & 122 & 220 & 240 & $308^{6}$ & $410^{6}$ \\
\hline Endividamento Geral (\%) & 35 & 59 & 63 & 78 & 100 & $118^{7}$ & $135^{7}$ \\
\hline
\end{tabular}

Fonte: Dados da pesquisa.

Legenda: ${ }^{4}$ Função Polinomial $\left(y=0,0989 x^{2}-396,73 x+397809\right)$, e $R^{2}=0,9028 .{ }^{5}$ Função Polinomial $\left(y=0,0054 x^{2}-\right.$

$21,714 x+21685), e^{2}=0,9932 .{ }^{6}$ Função Polinomial $\left(y=0,0632 x^{2}-253,35 x+254078\right)$, e ${ }^{2}=0,9242 .{ }^{7}$ Função Polinomial $\left(\mathrm{y}=0,0044 \mathrm{x}^{2}-17,559 \mathrm{x}+17490\right), \mathrm{e} \mathrm{R}^{2}=0,9602$.

O grau de imobilização do PL revela-se ascendente no período de $20 \mathrm{x} 0$ a 20x4, sendo assim, a organização está imobilizando o PL na aquisição de máquinas, móveis, informática e veículos. A análise horizontal complementa que de 20x0 a 20x4 a imobilização do PL apresenta uma tendência crescente na qual houve um crescimento em 3,33 vezes. Na dependência bancária ocorreu um aumento de 20x0 a 20x4 em 2,67 vezes do valor da carteira de empréstimos, assim como o endividamento geral que teve um aumento em 2,85 vezes de $20 \mathrm{x} 0$ a 20x4, confirmando um maior volume de obrigações adquiridas. 
A geração da linha de tendência pela função polinomial de grau 2 (GRÁFICOS 2), revela que houve uma precisão no ajuste desta com os dados históricos de 90,28\% (participação do capital de terceiros), 90,4\% (imobilização do PL), 99,3\% (dependência bancária) e 96,0\% (endividamento bancário).

Gráfico 2 - Regressão dos participações de capitais

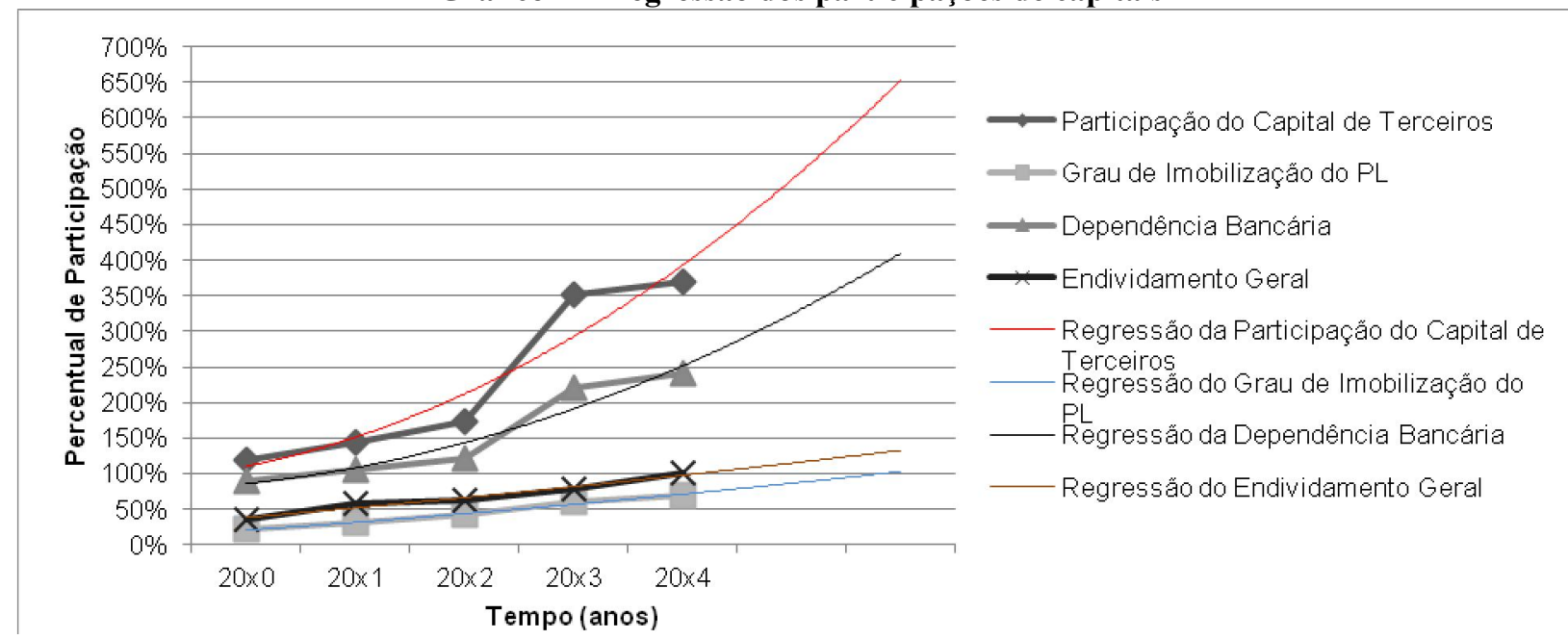

Fonte: Dados da pesquisa.

O coeficiente de determinação pode ser considerado alto, sendo assim, a previsão é confiável para 20x5 e 20x6. A tendência destes índices analisados apresentam uma piora, portanto a regressão reforça a situação desconfortável da entidade quanto a estrutura dos capitais.

\subsection{Análise da rentabilidade}

A rentabilidade do patrimônio líquido demonstra que os proprietários da organização não receberam lucros no período de 20x1 a 20x4, pois a rentabilidade demonstra resultados negativos, sendo assim, não rentabilizando o PL (TABELA 3). A margem líquida também é negativa, a empresa não apresenta uma margem para cobrir os custos necessários - que também é verificada na evolução da receita operacional. Portanto, percebe-se que o aumento da receita operacional é insuficiente para rentabilizar e suprir o capital circulante líquido.

Tabela 3 - Índice de Rentabilidade histórico e previsto

\begin{tabular}{l|c|c|c|c|c|c|c}
\hline & \multicolumn{3}{c|}{ Índices históricos } & \multicolumn{3}{c}{ Regressão (r2) } \\
\hline Rentabilidade do Patrimônio Líquido (\%) & $\mathbf{2 0 x 0}$ & $\mathbf{2 0 x 1}$ & $\mathbf{2 0 x 2}$ & $\mathbf{2 0 x 3}$ & $\mathbf{2 0 x 4}$ & $\mathbf{2 0 x 5}$ & $\mathbf{2 0 x 6}$ \\
\hline Margem Líquida (\%) & $-1,04$ & $-8,57$ & $-0,25$ & $-16,50$ & -20 & $-35^{8}$ & $-50^{8}$ \\
\hline Evolução da Receita Operacional (\%) & 1 & 1 & 20,87 & 30,49 & 42 & $58^{10}$ & $77^{10}$ \\
\hline
\end{tabular}

Fonte: Dados da pesquisa.

Legenda: ${ }^{8}$ Função Polinomial $\left(y=-0,0179 x^{2}+71,971 x-72258\right)$, e $R^{2}=0,7043 .{ }^{9}$ Função Polinomial $\left(y=-0,0023 x^{2}\right.$ $+9,2394 x-9279)$, e $R^{2}=0,5395 .{ }^{10}$ Função Polinomial $\left(y=0,0084 x^{2}-33,665 x+33702\right)$, e $R^{2}=0,9529$.

A regressão dos índices de rentabilidade evidencia um ajuste de precisão de $70,0 \%$ para a rentabilidade do PL, 53,9\% na margem líquida e 95,3\% na receita operacional (GRÁFICO 3). 
Gráfico 3- Linha histórica e de regressão da rentabilidade

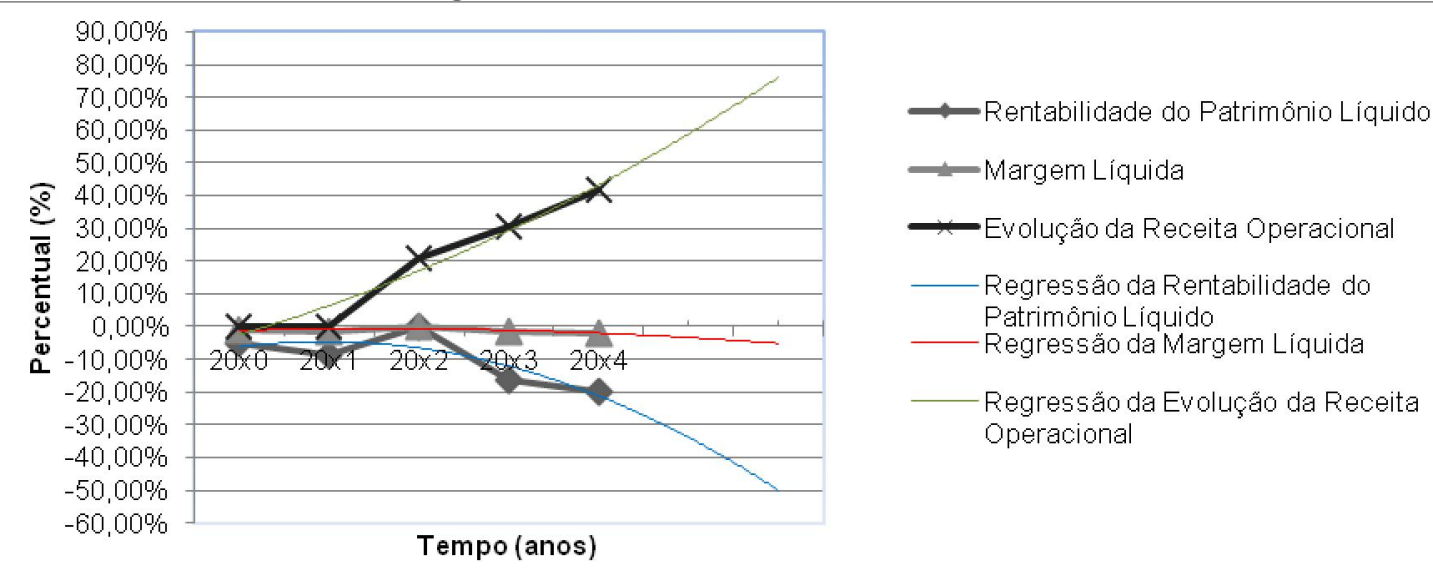

Fonte: Dados da pesquisa.

Os resultados da regressão dos índices de rentabilidade podem ser considerados como confiáveis e demonstram que a situação da rentabilidade foi prevista para um cenário negativo.

\subsection{Análise dos Índices de solvência}

O capital circulante líquido demonstra que há um excedente de ativo circulante em relação ao passivo circulante no curto prazo no período de 20x0 a 20x4 (TABELA 4). O capital de giro próprio, neste período, também se apresenta com excedente o que demonstra que a empresa consegue saldar suas obrigações com o próprio caixa. A NCG demonstra que em todos os períodos históricos a organização necessitou de recursos financeiros para financiar seus investimentos operacionais.

Tabela 4 - Índice de solvência histórico e a regressão

\begin{tabular}{|c|c|c|c|c|c|c|c|}
\hline & \multicolumn{5}{|c|}{ Índices históricos } & \multicolumn{2}{|c|}{ Regressão $\left(\mathbf{R}^{2}\right)$} \\
\hline & $20 \times 0$ & $20 \times 1$ & $20 \times 2$ & $20 \times 3$ & $20 \times 4$ & $20 \times 5$ & $20 \times 6$ \\
\hline $\mathrm{CCL}(\mathrm{R} \$)$ & $215.000,00$ & $201.319,00$ & $227.317,00$ & $167.862,00$ & $150.000,00$ & $97.000,00$ & $31.000,00^{\mathrm{II}}$ \\
\hline CGP (R\$) & $180.000,00$ & $171.319,00$ & $138.093,00$ & $76.103,00$ & $60.000,00$ & $1.000,00$ & $-52.000,00^{12}$ \\
\hline NCG (R\$) & $186.025,00$ & $135.000,00$ & $133.000,00$ & $145.000,00$ & $160.000,00$ & $212.000,00$ & $280.000,00^{13}$ \\
\hline
\end{tabular}

Fonte: Dados da pesquisa.

Legenda: ${ }^{11}$ Função Polinomial $\left(y=-6701,1 x^{2}+3 E+07 x-3 E+10\right)$, e $R^{2}=0,7841 .{ }^{12}$ Função Polinomial $(y=-$

$\left.3114,9 x^{2}+1 E+07 x-1 E+10\right), e R^{2}=0,9511 .{ }^{13}$ Função Polinomial $\left(y=10432 x^{2}-4 E+07 x+4 E+10\right), e R^{2}=0,8854$.

As linhas de tendências do Gráfico 4 revelam que a função polinomial de grau 2 apresenta uma precisão da regressão de 78,4\% para o CCL, 95,1 ao CGP e 88,5\% ao NCG. Estes resultados evidenciam que o coeficiente de determinação pode ser considerado alto, e desta forma, a regressão torna-se confiável. 
Gráfico 4 - Linha histórica e de regressão dos índices de solvência

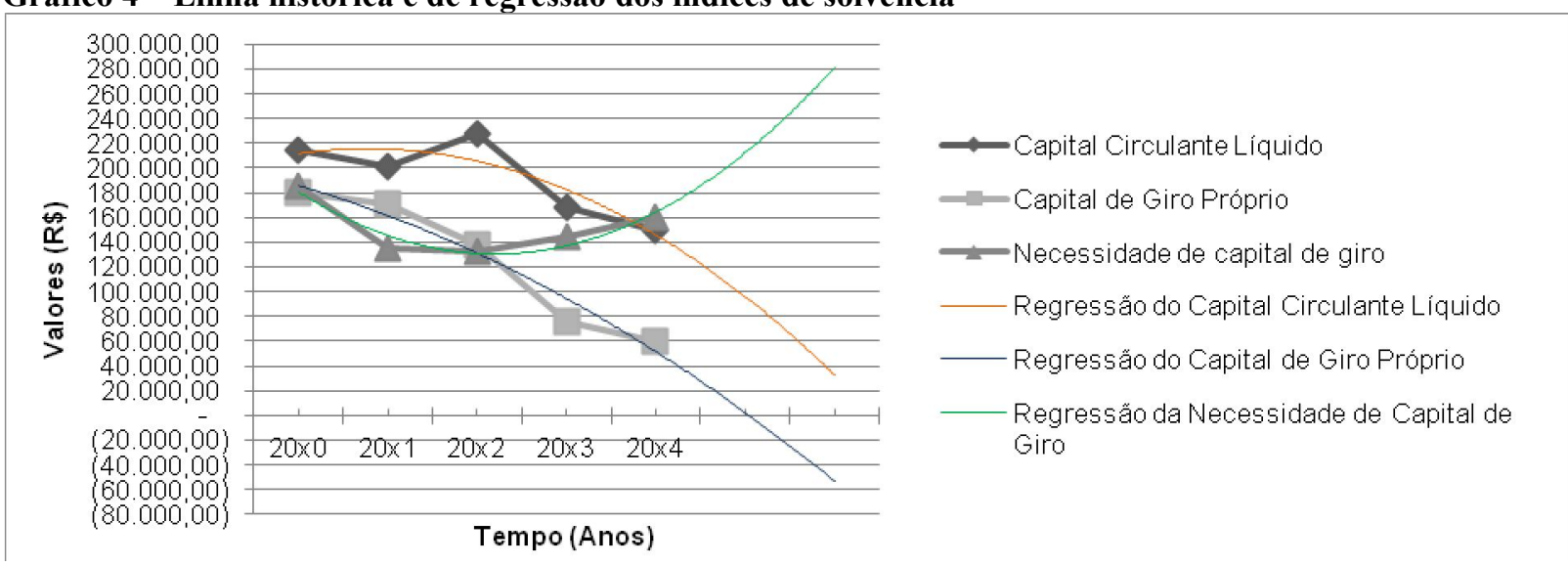

Fonte: Dados da pesquisa.

\subsection{Discussões dos resultados}

A análise dos índices de 20x0 a 20x4 revelam que a: a) liquidez apresenta-se em parâmetros aceitáveis quando comparado com padrões de Matarazzo (2008), e apresentam uma possível tendência de diminuição no período; b) estrutura de capital revela uma preocupação, pois além de apresentarem uma tendência de aumento, possuem seus quocientes elevados quando comparados com sugestões de Assaf Neto (2010) e Iudícibus (2010); c) rentabilidade demonstra que a margem líquida e a rentabilidade do patrimônio líquido são preocupantes, pois não apresenta lucro e logicamente não está rentabilizando o investimento do patrimônio líquido aos sócios, e além disso, a receita operacional teve aumento no período o que não refletiu nos índices anteriores; e d) solvência quanto ao CCL e CGP são positivos e possui uma possível tendência de declínio, porém a NCG apresenta uma possível elevação no período analisado, comparando-se com estudos de Padoveze (2004) e Matarazzo (2008) não se tem uma noção clara da situação apresentada.

A análise dos índices de 20x0 a 20x4 tendem a apresentar uma conclusão subjetiva referente a situação da organização analisada, pois torna-se difícil determinar um índice padrão e que pode ser utilizado como referência face as diferenças da cultura organizacional. As corporações podem ter estratégias mais/menos agressivas dependendo de sua missão e valores, assim como as diferenças de porte, atividade e localização. Dados os fatos, os estudiosos demonstram modelos de apuração de índices padrões possíveis e não definitivos, pois podem alterar em função do espaço-tempo (SCHRICKEL, 2000; BLATT, 2001; PADOVEZE, 2004; SILVA, 2004; MATARAZZO, 2008; IUDICIBUS, 2009; ASSAF NETO, 2010).

Esta reflexão fortalece a subjetividade na análise das demonstrações pelo método tradicional, porém ao mesmo tempo não se pode degradar a importância destes índices, pois são essenciais quando utilizados para interpretar a evolução histórica, tais como o retorno, o modo de captação de recursos, o ciclo financeiro, a capacidade de pagamento das obrigações, entre outros. Ademais são direcionadores em tomadas de decisões, auxiliam na elaboração da estratégia organizacional e quando comparados com índices de outras empresas do mesmo ramo, porte e região demonstram uma visão holística dos negócios. Estes apontamentos são coerentes com apontamentos de Scalabrin e Alves (2003) e Brignoni e Ruberto (2015). 
Uma forma de atribuir consistência a análise destes índices é a utilização do método estatístico (BRIGNONI; RUBERTO, 2015). Com a apuração e análise prévia dos índices pelo modelo tradicional, os dados tornam-se valiosas informações para a realização de testes de cenários futuro, tendências e/ou regressões. Neste sentido, a utilização da regressão polinomial, nos periodos 20x5 e 20x6, dos índices na abordagem integrada de análise apresentam uma média do $\mathrm{R}^{2}=0,8529$, o que significa que o modelo possui uma exatidão da previsão de $85,29 \%$ (TABELA 5).

Tabela 5 - Precisão de ajuste da regressão

\begin{tabular}{|c|c|}
\hline Índices & $\mathbf{R}^{2}$ \\
\hline Liquidez Corrente & 0,9110 \\
\hline Liquidez Geral & 0,9392 \\
\hline Liquidez Seca & 0,6460 \\
\hline Participação do capital de terceiros & 0,9028 \\
\hline Grau de imobilização do PL & 0,9602 \\
\hline Dependência Bancária & 0,9242 \\
\hline Endividamento Geral & 0,9932 \\
\hline Rentabilidade do Patrimônio Líquido & 0,7043 \\
\hline Margem Líquida & 0,5395 \\
\hline Receita operacional & 0,9529 \\
\hline Capital Circulante Líquido & 0,7841 \\
\hline Capital de Giro Próprio & 0,9511 \\
\hline Necessidade de Capital de Giro & 0,8854 \\
\hline Média & $\mathbf{0 , 8 5 2 9}$ \\
\hline Desvio Padrão & 0,1359 \\
\hline Coeficiente de variação & 0,1593 \\
\hline
\end{tabular}

Fonte: Dados da pesquisa.

O coeficiente de variação do $\mathrm{R}^{2}$ enquadra-se como médio, ou seja, apresenta uma boa precisão de que a média de 0,8529 pode ser utilizada para representar o $\mathrm{R}^{2}$ dos índices analisados, segundo apontamentos de Pimentel e Gomes (2000). Sendo assim, o $\mathrm{R}^{2}$ médio pode ser aceito como confiável e de possível aplicação prática deste modelo como análises de cenários futuros, o que também é defendido nos estudos de Callegari-Jacques (2003), Motta (2006), Webster (2006) e Brignoni e Ruberto (2015).

As possíveis tendências cogitadas na análise tradicional se confirmam na utilização da regressão polinomial com uma confiabilidade de $85,2 \%$, demonstrando uma projeção preocupante frente aos resultados dos índices. Cabe destacar que a utilização das ferramentas estatísticas, neste caso, evidencia a situação da empresa em 20x6, com dois anos de antecedência, e assim, há a possibilidade de elaborar estratégias pelos gestores para direcioná-la a otimização dos resultados e/ou estabilidade, em especial, aos de rentabilidade.

Os estudos da análise integrada por meio da estatística centram-se na determinação da insolvência, tais como de Araújo (2011), Costa, Andrade e Silva (2013), Horta, Alves e Carvalho (2014), Kleinert (2014), Girão (2015), entre outros. Entretanto, esse estudo possui a abordagem na geração de valor para a organização, ou seja, um modelo que auxilia na determinação da solvência por meio de estratégias e metas adequadas para melhorar a rentabilidade, condizente com estudos de Scalabrin e Alves (2003), Tsaousoglou, Aretoulis e Kalfakakou (2013), Brignoni eRuberto (2015), entre outros. 


\section{Considerações Finais}

O escopo central deste estudo foi apresentar um modelo de análise das demonstrações contábeis por meio do enfoque integrado e estruturado com regressão não-linear. Sendo assim, os resultados apontam que a análise tradicional das demonstrações contábeis por meio de índices não pode ser ignorada, pois representam os principais meios da avaliação do desempenho da organização.

Entretanto, utilizar a análise tradicional como única forma de elaborar uma conclusão sobre a situação da empresa, parece preocupante, pelo grau de subjetividade utilizada neste processo, pois possuem como alicerce apenas os dados históricos, havendo dificuldade de determinar se o resultado do índice é satisfatório ou não, os índices padrões auxiliam, mas deve-se observar a atividade, o porte, a cultura organizacional, missão, valores, entre outros.

Além da análise tradicional a inclusão da análise integrada revela que a conclusão da análise torna-se menos subjetiva. Atribui à análise confiabilidade e maior precisão na elaboração da sua conclusão, e ainda, torna-se um meio essencial na tomada de decisões consistentes e seguras. Assim, a análise integrada utilizada na elaboração do modelo deste estudo demonstra que a regressão antecipa o futuro da empresa, e portanto, poderia fornecer um mecanismo de alarme quando a previsão apontar para índices com valores críticos. Desta forma a organização tende a melhorar a capacidade de identificação de dificuldades financeiras no futuro, pois este aviso prévio pode dar a empresa tempo para a elaboração de estratégias para evitar futuras dificuldades financeiras ou falência.

Infere-se, portanto, que para uma análise mais confiável e eficaz, além da análise tradicional seja incluída uma previsão para analisar o futuro da corporação. Com estas informações futuras o analista poderá prover os tomadores de decisão com uma visão proativa dos acontecimentos antes do ocorrido, podendo-se alterar o rumo da corporação.

\section{Referências}

ARAUJO, M. B. V. Informações contábeis e o risco de insolvência de cooperativas de crédito. 2011. Tese de Doutorado. Universidade de São Paulo.

ASSAF NETO, A. Estrutura e análise de balanço. São Paulo: Atlas 2010.

AZEREDO, A. J. Desempenho econômico-financeiro de indústrias calçadistas brasileiras: uma análise do período de 2000 a 2006. 2008. 249 f. 2008. Dissertação (Mestrado em Ciências Contábeis) Programa de Pós-graduação em Ciências Contábeis, Universidade do Vale do Rio dos Sinos-UNISINOS, São Leopoldo, RS.

BASSANEZI, R.C. Ensino-Aprendizagem com modelagem matemática. $3^{\text {a } e d . ~ S a ̃ o ~ P a u l o: ~}$ Contexto, 2006. 389 p.

BLATT, A. Análise de balanços: Estrutura e avaliação das demonstrações financeiras e contábeis. São Paulo: Makron Books, 2001.

BRAGA, H. R.; ALMEIDA, M. C. Mudanças contábeis na lei societária: Lei nº 11.638, de 2812-2007. São Paulo: Atlas, 2008. 
BRAGA, R.; NOSSA, V.; MARQUES, J. A. V. C. Uma proposta para a análise integrada da liquidez e rentabilidade das empresas. Rev. contab. finanç. v.15, p. 51-64, 2004,

BRIGNONI, T.; RUBERTO, I. V. G. Análise de regressão linear na projeção de resultados em empresas do ramo de cosméticos e higiene pessoal. 2015. Disponível em: http://www.unicruz.edu.br/site/cursos/contabeis/artigos/Artigos\%202015/

Analise $\% 20 \mathrm{de} \% 20$ regressao $\% 20$ linear $\% 20$ na $\% 20$ projecao $\% 20 \mathrm{de} \% 20$ resultados $\% 20 \mathrm{em} \% 20 \mathrm{emp}$ resas $\% 20 \mathrm{do} \% 20 \mathrm{ramo} \% 20 \mathrm{de} \% 20 \operatorname{cosmeticos} \% 20 \mathrm{e} \% 20$ higiene $\% 20$ pessoal.pdf Acesso em 25 janeiro 2016.

CALLEGARI-JACQUES, S. M. Bioestatística: princípios e aplicações. 1. ed. Porto Alegre: Artmed, 2003.

CHANG, W.; CHANG, K. W.; HSIN, J. Y. Analysis of Financial Performance by Strategic Groups of Digital Learning Industry in Taiwan. Journal of American Academy of Business, Cambridge, v. 10, n. 1, p. 298-304, 2006.

COSTA, D. M. D.; ANDRADE, D. C. T.; SILVA, C. A. Análise dos modelos de previsão de insolvência sobre as empresas de capital aberto do setor aéreo do brasil. In: $5^{\mathrm{a}}$ Jornada Cientifica e Tecnológica e $2^{\circ}$ Simpósio da Pós-Graduação. 2013.

Exame. Crescem pedidos de falência e de recuperação judicial. 2016. Disponível em: http://exame.abril.com.br/economia/noticias/crescem-pedidos-de-falencia-e-de-recuperacaojudicial. Acesso em janeiro 2016.

FRANCO, H. Estrutura, análise e interpretação de balanços. São Paulo: Atlas, 15 ed. 1989.

GIRÃO, A. P. P. Previsão de insolvência nas PME: o setor das empresas comercializadoras de materiais de construção. 113f. Dissertação de Mestrado em Gestão na Faculdade de Economia da Universidade de Coimbra, Coimbra, 2015.

GIL, A. C. Métodos e técnicas de pesquisa social. 5. ed. São Paulo: Atlas, 1999.

HENDRIKSEN, E. S; VAN BREDA, M. F. Teoria da contabilidade. São Paulo: Atlas, 2009.

HOJI, M. Administração financeira: uma abordagem prática. - 5. ed. - São Paulo: Atlas, 2004.

HORTA, R. A. M.; ALVES, F. J. S.; CARVALHO, F. A. A. Seleção de atributos na previsão de insolvência: aplicação e avaliação usando dados brasileiros recentes. RAM, Rev. Adm. Mackenzie [online], v.15, n.1, p. 125-151, 2014.

HOUSTON, J.; BRIGHAM, E. F. Fundamentos da moderna administração financeira. Rio de Janeiro: Campus. 1999. 
IUDÍCIBUS, S. Existirá a contabilometria? Revista Brasileira de Contabilidade, n.41, p. 4460, 1982.

IUDICIBUS, S.; MARTINS, E.; GELBCKE, E. R. Manual de contabilidade das sociedades por ações: aplicável às demais sociedades. 7. ed. São Paulo: Atlas, 2007.

IUDÍCIBUS, S. Análise de Balanços. 10ª Ed. Atlas. São Paulo. 2009.

MARION, J. C. Análise das demonstrações contábeis. 6.ed. SÃO PAULO: Atlas, 2010.

MARTINS, E. Análise crítica de balanços. Parte 1. Boletim IOB. Temática Contábil e Balanços. Bol. 26. 2005.

MATARAZZO, D. C. Análise financeira de balanços: abordagem básica e gerencial. 6. ed. São Paulo: Atlas, 2008.

MEUSE, K. P.; BERGMANN, T. J.; VANDERHEIDEN, P. A.; RORAFF, C. E. New Evidence Regarding Organizational Downsizing and a Firm's Financial Performance: a long term analysis. Journal of Managerial Issues, v. 16, n. 2, p. 155-177, 2004.

MOTTA, V. T. Bioestatística. 2. ed. Caxias do Sul, RS: Educs, 2006.

MYERS, S. C. Capital structure. Journal of Economic Perspectives, v. 15, n. 2, 2001.

NATRELlA, M. C. C.; TOBIAS, P.; FILlIBEN, J J.; BARRY, H.; GUTHRIE, W.; LEDITRUTNA, J. P. NIST/SEMATECH e-hand book of statistical methods. 2010. Disponível em: http://www.itl.nist.gov/div898/handbook/ Acesso em janeiro 2016.

NIEMANN, M.; SCHMIDT, J. H.; NEUKIRCHEN, M. Improving performance of corporate rating prediction models by reducing financial ratio heterogeneity. Journal of Banking \& Finance, n. 32, p. 434- 446, 2008.

OCAL, M. E.; ORAL, E. L.; ERDIS, E.; VURAL, G. Industry financial ratios-application of factor analysis in Turkish construction industry. Journal of Building and Environment, n. 42, p. 385-392, 2007.

OLIVEIRA, A. B. S. Métodos da pesquisa contábil. São Paulo: Atlas, 2011.

PADOVEZE, C. L. Contabilidade gerencial: Um enfoque em sistema de informação contábil. 4. ed. São Paulo: Atlas, 2004.

PEREIRA, A. F. A.; PEDROSA JÚNIOR, C. P.; RAMOS, E. J. S. Modelo e análise de previsão de desempenho pela metodologia de análise multivariada de dados: um estudo empírico do setor de energia elétrica. Revista Contemporânea de Contabilidade, ano 03, v.01, n.5, p. 59-74, 2006. 
PEROBELli, F. F. C.; PEREIRA, J. F.; DAVID, M. V. Relação Liquidez-Retorno: existiria também uma "Estrutura de Liquidez" Ideal para cada Perfil de Empresa? Salvador, BA: Enanpad, 2006.

RAMALHO, J. S.; SILVA, J. Vidigal. Functional form issues in the regression analysis of financial lever age ratios. Empirical Economics, v. 44, n. 2, p. 799-831, 2013.

SAPORITO, A. Análise referencial: proposta de um instrumento facilitador da análise a longo prazo de demonstrações contábeis. São Paulo: USP, 2005.

SANTOS, A.; NOVA, S. P. C. Proposta de um modelo estruturado de análise de demonstrações contábeis. RAE-eletrônica, v. 4, n. 1, 2005.

SCALABRIN, I.; ALVES, T. W. Os indicadores contábeis podem prever a geração de valor. XXVII ENANPAD, 2003.

SCHRICKEL, W. K. Análise de Crédito - Concessão e Gerência de Empréstimos. $5^{\mathrm{a}}$ ed. São Paulo: Atlas, 2000.

SERASA. Número de recuperações judiciais bate recorde histórico em 2015.Disponível em: http://noticias.serasaexperian.com.br/numero-de-recuperacoes-judiciais-bate-recorde-historicoem-2015-revela-serasa-experian/.Acesso em janeiro 2016.

SILVA, E. L.; MENEZES, E. M. Metodologia da pesquisa e elaboração de dissertação. ed. rev. atual. - Florianópolis: UFSC, 2005.

SILVA, J. P. Análise financeira das empresas. 6. ed. São Paulo: Atlas, 2004.

SILVA, J. P. Gestão e análise financeira de risco de crédito. 5. ed. São Paulo: Atlas, 2006.

SILVA, M. C.; CHACON, M. J. M.; SANTOS, J. O que é contabilometria? Revista Pensar Contábil CRC - RJ. Rio de Janeiro, ano VII, n. 27, p. 40-43, 2005.

TSAOUSOGLOU, A. P.; ARETOULIS, G. N.; KALFAKAKOU, G. P. Forecasting the Trends of Financial Ratios of Greek Construction Companies. International Journal of Data Analysis and Information Systems, v. 5, n. 1, p. 51-63, 2013.

WEBSTER, A. L. Estatística aplicada à administração e economia. 1. ed. São Paulo: McGraw-Hill, 2006. 633 p.

WEBGRAPHING. Polynomial tricks of trade. 2013. Disponível em http://www.webgraphing.com/polynomialtricksoftrade.jsp Acesso em dezembro de 2015. 